\title{
Where the Place of Technology in Mathematics?
}

\author{
Fitriati Fitriati
}

\author{
Department of Mathematics Education,STKIP Bina Bangsa Getsempena, Banda Aceh, 24355, Indonesia \\ fitriati@stkipgetsempena.ac.id \\ ${ }^{*}$ Corresponding Author \\ Whatsapp Number \{+62-81269820041\}
}

How to Cite : Fitriati, F. (2019). Where the Place of Technology in Mathematics?. International Journal for Educational and Vocational Studies, 1 (2), $92-99$.

\section{ARTICLE HISTORY}

Received:2 May 2019

Revised: 21 May2019

Accepted: 29 May 2019

KEYWORDS

Technology

Mathematics

Education

\begin{abstract}
Technology integration in mathematics instruction is demanded throughout educational system as it offers to support students achievement, teachers productivity, and effectiveness in the classroom management. However, its implementation has presented some complex problems including lack of specific knowledge and skills of technological tools, diversity of points of view and beliefs, and the factor of time. This indicate that integrating technology to improve mathematics education is a challenging task. To ensure technology is used effectively to enhance students' learning and teachers' practice of mathematics, many facets need to be considered. Australian curriculum clearly mandated educational stakeholders to use technology to support daily mathematics instruction, but a direction of how to apply it in the classroom still unclear. It is suggested that more emphasize on rich mathematical tasks, productive pedagogies and developing teacher professional development that foster both technological competence and pedagogy flexibility as proposed by many educational researchers is needed.
\end{abstract}

\section{INTRODUCTION}

There is the optimism in educational circles about possibilities new technology offer to support K-12 learners' achievement, teachers' productivity, effectiveness in classroom and teacher learning in mathematics (Borko, Whitcomb \& Liston, 2009, Laborde \& StraBer, 2010; Lynch, 2006, Thomas, Tyrrell \& Bulloc, 1996). Research has been recognised that the implementation of technology integration through effective use of mathematical software, spreadsheets, graphics and CAS calculators and data logging equipment enables fast, accurate computation, collection and analysis of real or simulated data (Rochelle, Schehtman, Tatar, Hedegus, Hopkins et al., 2010). These technologies also enable investigation of links between numerical, symbolic, and graphical representations of mathematical concepts (Goos, 2010). The belief of this integration has led many governments to develop policies to promote learning and the use of digital technology throughout education system for mathematics learning (Hew \& Brush, 2006; Julie, Leung, Thanh, Posadas, Sacritan \& Samenov, 2010; Vale, Julie, Buteau \& Ridgway, 2010).

In Australia, the governments have clearly taken up of transforming schools to meet the challenges of the information age. Throughout Australia there are moves to
This is an open access article under the CC-BY-SA license.

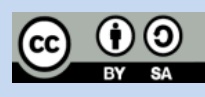

encourage the integration of digital technologies into school education through curriculum initiatives, funding for infrastructure, and the development of professional standards for teachers (Goos, 2008; Brady \& Kennedy, 2007). This can be found in the proposed of new Australian curriculum in which the use of ICT in mathematics curriculum is clearly mandated (ACARA, 2010). However, a number of study on the use of ICT in teaching and learning mathematics has shown that the ICT integration is still problematic. Its integration into mathematics teaching and learning has presented some complex problems (Borko, et al., 2009; Hew \& Brush, 2006; Laborde \& StraBer, 2010). These problems include the issues around mediation of mathematical content through technology, conceptual and practical differences when teaching and learning with new technology, the necessary change of tasks and the most crucial one is teacher education. Additionally, many studies have shown that access to technology resources, institutional support, and educational policies are insufficient conditions for ensuring effective integration of technology into teachers' everyday practice (Goos, 2010). These findings show that there is obviously a tension between the policy of advocating the use of technology in mathematics curriculum and the reality of its use in the 
mathematics classroom. This indicates that the transition to technology paradigm has proved to be one of major challenges for mathematics curriculum developers. There is need for new direction for curriculum to ensure that the use of technology in mathematics classroom are relevant to teachers, particularly, students.

A call for new curriculum that takes into account all those challenges by providing some strategies to overcome such problems is necessary. As there have been many calls to design the curriculum with regard to technology integration, this paper proposes some key considerations how should new mathematics curriculum be designed to meet the needs and possibilities. The discussion of this paper is divided into three parts. A review of the place and use of new technology in mathematics curriculum are firstly provided. This section will provide a background of Australian mathematics curriculum and highlight some contributions of technology in mathematics curriculum. After providing background on mathematics curriculum and technology roles this paper gives an overview of some issues that have been emerged since the technology integration in mathematics curriculum. This includes diversity of attitude toward technology, the complexity of the process, and teacher knowledge. The last part will discuss how new mathematics curriculum should be designed with technology integration. This discussion of this section will look at content (mathematical concepts) and pedagogies aspect that should be considered. This paper concludes by suggesting some recommendations as it is noted that integrating technology into mathematics learning and teaching is not simple matter. There are many aspects need to be considered such as possibilities and issues around its integration.

\section{MATHEMATICS CURRICULUM IN AUSTRALIA}

Mathematics education in Australia is currently experiencing major impetus for innovation and reform. The Australian Government's policy statements on educational innovation and teacher quality (Commonwealth of Australia, 2001, 2003) emphasize that Australia's future lies in its potential as a knowledge-based society built on the intellectual capabilities and creativity of its people. Teachers and students are expected to become partners in a learning society underpinned by utilizing the resources of technology to facilitate learning. Since the late 1990s computer integration has been formally mandated in government curriculum frameworks, and, using terminology such as information and communication technology and e-learning, state curriculum frameworks continue to promote the integration of new digital technologies (Goos, 2008). For example, in Western Australia, the integration of digital information and communication technologies into the curriculum is a significant aspect of the "Plan for Government Schools 2004-2007" (Western Australian Department of Education \& Training, 2003). In Victoria, further to that state's curriculum framework, government schools are required to formulate policy documents that position computer technology as an integral part of school learning (Victorian Curriculum \& Assessment Authority, 2002, 2005). The current National Australian Curriculum design, in the shape of the Australian Curriculum for mathematics, states that available technology should be used for teaching and learning situation (ACARA, 2010). Specifically, the proposed curriculum mentions several technology stuffs that should be used such as computer algebra system, graphing packages, financial and statistical packages and dynamic geometry that can be implemented through either a computer or calculator. The shape of the Australian Curriculum for mathematics expects that using technology can aid in developing skill and allay the medium of repeated calculations. For example, a technology can be used to complete recursive calculation (Draft Consultation version 1.1.0, 2010). Moreover, the curriculum suggests utilizing available resources on the internet, in particular, in state and territory portal that have application for learning and teaching mathematics. This indicates that the proposed curriculum has addressed of what and why of technology integration in mathematics. However, there is no specific direction or standards how should the technology be employed in order to ensure all achievement targets are gained by students. It is required that the curriculum must provide this direction so that stakeholders could implement it properly. In short, the place of technology in mathematics has been valued in Australian curriculum as its roles in mathematics curriculum are pivotal for improving learning and teaching mathematics. These will be reviewed in the following section.

\section{TECHNOLOGY IN MATHEMATICS CURICULUM}

Technology has been use throughout the history of mathematics education. Many ancient and modern societies used an abacus both as procedural tool and as conceptual model of arithmetic. In the nineteenth century, squared paper was used as an instrument in teaching mathematics (Laborde \& StraBer, 2009). More recently, most elementary schools have introduced use of physical manipulatives, such as Diene' Blocks, for introducing and other arithmetic concepts (Rochelle et al., 2010). It is also found that scientific calculator and graphing calculator are common in secondary schools. The most prominent, recent and modern tool that is called new technology, which includes computer, software and communication technology, are used widely in many education levels across the nations. Computer software for mathematics learning can take many forms and operate through different cognitive mechanisms. Software can provide students with opportunities for practice and rapid feedback in a motivating environment or have higher order cognitive goals (Wenglinksy, 1998). Programming tools can provide opportunities for students to write mathematical programs, and developmental principles suggest that constructing programs can lead to constructing knowledge (Roschelle et al., 2010). And there are many technology tools have been designed that is dedicated to development of mathematics learning and teaching in order to make computation easier, 
more accurate and faster as well as develop students' conceptual understanding of mathematical functions. According to Stacey (2005), these works have been done because digital technology affects mathematics and mathematics teaching very fundamentally. Therefore, it is obvious that technology supports both computational and representation. In particular, technology can support mathematical ideas in ways that are important for conceptual understanding.

Given long history of technology in mathematics curriculum and the many differences in approach and application, it seems that technology and mathematics education cannot be separated. Mathematics educators, teachers or technology developers always try to find a method or tool that makes mathematics learning easier and faster for students and the most important thing is to foster students advance in mathematics. Regarding this, all education stakeholders advocate the enhancement of learning with technology. Consequently, technology is becoming infrastructure in mathematics education (Kaput, 2007).

There are several reasons why using technology in mathematics education is essential. Most of reasons are raised because of its contributions to enhance mathematics learning. The primary motivation for integrating ICT in education is the belief that it supports students in their own constructive thinking, allows them to transcend their cognitive limitations, and engages them in cognitive operations (Lim, 2007). This reason is also supported by Naeve and Nilsson (2007) who argue that mediating mathematics learning with technology can increase cognitive contact in different ways such as by clearly expressing mathematical context as well as by visualizing the mathematical concepts and interacting with the form behind the mathematical formulas. It is believed that this kind activity could construct better understanding of students. According to Stacey (2005), applying these could motivate and keep students' interest in learning mathematics.

Another reason is that technology provides new techniques for performing task. Technology enable students to explore, describe, estimate, solve and develop mathematical concepts. For example, computer provides a wide range of functionality including word processing, drawing, database, and spreadsheet facilities that can facilitate students to perform mathematical activities, particularly, solving problem which is the main activity in learning mathematics. They also can use statistics packages to generate large list of recursive numbers quickly and create graphical presentation. Another evidence on this integration has been disclosed by Rochelle, Pea, Hoadley, Gordin \& Means (2000) who conduct a SimCal project, which shows that using dynamic, linked notations, computers can help middle school students in some of the most challenging urban settings to learn calculus concepts such as rate, accumulation, limit and mean value. With technology, therefore, students can amplify their abilities to solve mathematical problems or reorganize the ways they think about problem and solution. These evidences show that technology can serve as a catalyst for the changes in the content, roles, and organizational climate that are required for a shift from traditional to constructivist instructional practices (Matzen \& Edmunds, 2003).

Finally, technology also has significant pedagogical implications for teachers. Rochelle et al. (2000) noted that the structure and resources of traditional classrooms often provide quite poor support for learning, "whereas technology--when used effectively can enable ways of teaching that are much better matched to how children learn" (p.79). Many types of learning networks such as Mathletics, Nrich, The Learning Federation and The National Science Digital Library (NSDL) and teacher TV have been created for use in the classroom. There are many ways in which teaching practice might change when these new online learning are adopted in the classroom. For example, as many schools in Australian have used Mathletics, a web based learning program which integrates home and school leaning via internet, teachers may no longer need to prepare and explain the lesson to students as regular mathematical routine because Mathletics offers full K-12 curriculum coverage and support centre in which students can access step by step animated support for every mathematics concepts. This seems that this learning environment shifts new roles of teachers in promoting learning is required. It can be concluded that technology has changed teachers' pedagogies in many ways.

There are still many contributions of technology to mathematics education development as found in many literatures. However, this paper provides only some of them on the section as analyzing these contributions of technology is essential for curriculum developers who need to specifically reframe the goals of mathematics education in a technological environment. This is inlined with Roschelle et al. (2000) who argue that substantial curriculum adjustment is required if technology will be integrated into classroom. Exactly this is important in thinking how these goals are achieved.

\section{THE ISSUES OF INTEGRATING TECHNOLOGY IN MATHEMATICS CURRICULUM}

Although research studies in mathematics education show that use technology can help student learning, its integration generally has presented some complex problems (Borko et al., 2009; Hew \& Brush, 2006; Laborde $\&$ StraBer, 2010). Among these problems is that prevalent barriers related to the integration of technology into the mathematics curriculum that are currently faced by K-12 schools. One of the biggest barriers to introducing effective technology applications in classrooms is that lack of specific knowledge and skills of technological tools. Many studies found that lack of specific technology knowledge and skill is one of the common reasons given by mathematics teachers for not using technology (Hew \& Brush, 2006; Kendal and Stacey, 2002; Snoeying \& Ertmer, 
2001). For example, Kendal and Stacey (2002) in their study on how two mathematics teachers made the transition from using graphic calculators to CAS calculator while teaching differential calculus to upper secondary school students in Melbourne found that teachers did not use this technology tool into mathematics activity until they had developed their skills of CAS calculator. This shows that teachers are uncomfortable with teaching the lessons that they are not capable with. As the result, this may affect their teaching practice in the classroom.

Additionally, the use of technology in mathematics curriculum has given rise to a diversity of points of view and beliefs. This is especially teachers' and students' belief about technology can support mathematics learning. According to Ertmer (2005), the decision of whether and how to use technology for instruction ultimately depends on the teachers themselves and the beliefs they hold about technology. Many researchers found that teachers' beliefs about technology to be a major barrier to technology integration (Goos, Lavergne, Assuse, Brown, Kong et al., 2010; Newhouse, 2001; Hew \& Brush, 2006). For example, a study in Australia that investigated the perceptions of students and teachers towards the use of portable computers at a secondary school revealed that the majority of teachers believed that computers would not lead to better understanding or faster learning (Newhouse, 2001). On other hand, another study on a comparison between Australian and Singaporean teachers' views which was conducted by Forgasz, Griffith and Tan (2006) found that in general, teachers viewed the graphic calculator as a useful tool to support their teaching and students learning on mathematics. Additionally, the diversity of perceptions also comes from students. For instance, Ben Mechaiekh, Buteau \& Ralph (2007) report that most high school graduates see mathematics as a set of roles and procedures and have little experience using technology to support and enhance their own learning of mathematics. Many students in that study were reluctant to get involved with computer programming. In Another study, Li (2007) examines student concern and resistance in toward spreadsheets in mathematics instruction. He found that students generally had a mistrust of software and felt more comfortable with their traditional method of learning. These different perceptions make school difficult to employ technology. In other word, the diversity of views has caused the impediment of the implementation of technology in school, in particular mathematics classroom.

Finally, the factor of time is also recognized as a problem for integrating technology. It has been reported that "the time and effort needed by both students and teachers in order to become familiar with technology" (Thomas, 2006, p. 7). Teachers need more time to prepare themselves with all the materials needed for teaching with technology. For example, when teaching mathematics with computer algebra system, teachers may spend more time to teach student on how to operate this tool properly, and to explain what mathematical theory behind the tool is. This is also problematic when class time available is insufficient for students to use the computer (Assude et al., 2010). In addition, teachers need hours to preview websites to find the information on a global view of how the teaching of certain contents is progressing, and to have an idea of what kind of approach is better to apply and what has to come for an activity in the classroom. This problem is common for teachers who just change their pedagogy from traditional method to technological approach. According to Assude (2005, p. 200), "Even experienced teachers are not necessary ready to face time management difficulty when the way of working with the class changes". Considering this, many teachers might avoid to use technology-related activity. In short, it is clear that lack of time is another obstacle in implementing technology in mathematics classroom.

As discussion above has mentioned some contributions of technology in mathematics curriculum as well as some major issues related to its implementation, therefore it is clearly show that the problem of technology implementation is complex. Some factors can foster this implementation in some situation yet impede implementation in other (Assude et al., 2010). There is indication that the change in mathematics knowledge and mathematical practices that are emerging in the digital age are more difficult to implement in school classroom. However, this does not mean that technology-related activity should be avoided in mathematics classroom. Many changes and ongoing efforts are needed to integrate technology into the mathematics curriculum. Looking back at a number of study on technology in mathematics education and reflection on the gap between aspirations and reality regarding technology integration in mathematics classroom, it is required how new curriculum should be designed to meet all needs and possibilities? What should be taught? And how should be taught? The following section will provide some suggestions regarding these questions.

\section{NEW CURRICULUM}

Schools today face increasing demands in their attempts to ensure that students are well equipped to enter the work force and navigate the complex world. This can be seen from many efforts that have be done in setting more challenging goals in national standard and state curriculum framework document (ACARA, 2010; Roschelle et al., 2000). In mathematics curriculum, for instance, one of efforts is incorporating ICT in the learning as it is believed that ICT could help support learning, especially, useful in developing the higher order skills of critical thinking, analysis and scientific inquiry (Hew \& Brush, 2006; Naeva \& Nillson, 2007; Rochelle et al., 2000). However, implementation this promising application is still challenges. Exploring various ways that technology can be used to improve how and what students learn mathematics in the classroom is needed. 


\subsection{Content: what should we teach?}

Research has demonstrated that technology can lead to profound changes in what students learn. Mathematics activities may change as a demand of the appearance of new pedagogical tools in the curriculum. Most of the debate around the subject of curriculum content associated with technology is centered on the aspects of sequencing, and inclusion or exclusion of particular topics. For example, Oates (2009) mention a question almost universally asked, particularly in respect to CAS, is "What will be left to teach if students have access to tools which draw graphs, factorizes and solve equations, and perform differential calculus?. Additionally, some studies do consider the effect of technology on the position of specific content areas in the curriculum. For instance, the place of geometry in the curriculum has progressively lessened by the move away from rigor and formalism. Dynamic geometry software allows students to develop experimental understandings of proof, and may thus have the potential to restore geometry to a significant place in the curriculum (Vincent \& McCrae, 2000). These evidences show that incorporating technology requires a change of contents that should be taught in the curriculum.

Regardless, the previous discussion on contents of curriculum, it is argued that focusing on mathematics content itself is less effective, but highlighting on leaning mathematics concepts might be appropriate. This concept-based learning can be realized by employing rich tasks. Many learning researchers argue that the most effective way of promoting learning is to embed basic skills instruction within more complex tasks (Roschelle et al., 2000). A task that can engage students in the learning process, make contents meaningful and foster connections among ideas and disciplines (Moulds, 2004). According to Fergusson (2009), tasks in which the whole class can engage and are easily adjusted to students level of ability. Consequently, many countries in the world have responsed to this by applying rich tasks within their school curriculum to prepare students to live in challenging world (Fitriati and Novita, 2018). This includes Queensland Study Authority (2001) that recommends the use of rich tasks to invigorate such learning by emphasizing this as a key concept in learning for K-12 schools.

The justification of why applying rich tasks in mathematics learning with technology as a better recommendation is because rich tasks allow students to learn mathematics from real world context which require higher order of thinking and comprehension understanding (Moulds, 2004; Stein, Grover \& Heningson, 1996), create opportunity for students to explore and articulate mathematical idea independently (Oslon \& Barret, 2004). Rich mathematical task also have the ability to reach the students at the points where their known understandings meet the unknown (Fergusson, 2009). It is argue that these activities can be facilitated by technology in particular computer technology or mathematical softwares which can provide students with an excellent tool for applying concepts in a variety of contexts and support the learning of these more complex skills and concepts. Additionally, digital technologies such as internet can make contribution for both students and teachers to approach the rich tasks. This includes limitless capacity to store information; the ease of accessing, searching and retrieving information from large databases; the ability to compare multiple documents from different sites that provide more complex and best experience (Borko et al., 2009). For instance, since education standards and curriculum guidelines throughout the world are challenging teachers to create more mathematics rich tasks such as creating problem-based learning activity (Moulds, 2004), teachers can access the information from many educational websites of what kinds of rich tasks suit for their students; find the best practice that has ever been done by other educators in other part of the world. At the same time students also can use this tool to approach the solutions of given rich tasks. It is believed that applying these rich tasks in mathematics learning may also solve current mathematics education problem in which students were failing to apply of what they learn in school to problems they encounter in the real world (Roschelle et al., 2000).

While the preceding discussion illustrates the positive contribution of rich tasks in promoting students mathematics learning, the implications for curriculum development may clear then. However, in the reality it seems different. Although current Australian mathematics curricular frameworks expect students to take active roles in solving problems, communicating effectively, analyzing information, connecting between the areas of mathematics and others disciplines, designing solutions focus on skills and utilizing technology tools to support learning (ACARA, 2010), the proposed design curriculum still focus on content based learning. This can be seen from a number of mathematics topics outlines that should be taught to students for each grade. It seems inconsistent that in one hand the proposed curriculum aims to ensure that students recognize connections among the concepts or other disciplines, but it also mandates teachers to teach a bunch of contents within a particular term on other hand. As discussion above points out that employing rich tasks has advantage over allowing students to learn mathematics from real world context which require higher order of thinking and comprehension understanding, which then this can be facilitated by using a number of technology tools, it is suggest that the current proposed Australian curriculum should create a challenging contents within more complex task to prepare students for $21^{\text {st }}$ century.

\subsection{Pedagogy: how should we teach?}

Most discussion about mathematics pedagogy suggest shift away from teaching procedures and skills to greater emphasis on process, problem solving and development of conceptual understanding (Schoenfeld, 1992; Oates, 2009). Since this is needed, it is argue that technology can play a key role in facilitating the shift in emphasis away of routines. Technology allows for greater experimentations; 
focus on problem solving and visualization; and increase the congruence between real mathematics and school mathematics and to encourage deeper learning (Assude et al., 2010; Stacey, 2003). For instance, Oates (2009, p. 62) mention that "CAS enriches many students' interactions and requires a change in the focus of exercises and the style of questions asked". It seems obvious that there are many ways in which teaching practice might change when new technology is introduced such as shifting from teacher-centered approach into more student-centered learning environment.

As it was noted earlier that rich task is highlighted as an activity in learning mathematics concepts with technology, the instructional approach suited this activity is pedagogies that are developed under constructivist learning theory frameworks. This learning theory proposes that learning will be meaningful when students get opportunity to construct their own knowledge (Steffe \& Wiegel, 1992). This is inlined with the current view on mathematical pedagogy that has placed an increased emphasized on building students' mathematical identities by asking students to play an active role in learning and setting the agenda for learning (Chinnapan, 2006). Therefore, it is suggested that problem based learning, project based learning or other collaborative learning as the best approach to promote the rich mathematical tasks. It is argued that the methods might be more effective because it present active engagement, participation in groups, frequent interaction and feedback, connection to real world context (Roschelle et al., 2000). Additionally, the approaches also capitalize of using technology as a tool in facilitating the learning (Grant and Branch, 2005).

To promote these learning approaches many researchers have suggested productive pedagogies framework. They have argued that more effective learning will be achieved if the learning promotes four dimensions of productive pedagogies: intellectual quality, connectedness, supportive classroom environment and valuing and working with difference (Mills, Goos, Keddie, Honan, Pedergast et al., 2009; Queensland Study Authority, 2001). One primary reason argued by Mills et al. (2009) for implementing productive pedagogies because it promotes provision of a high quality education in which students are provided with an effective learning environment that can stimulate intellectual activity. It is argued that pedagogies that integrate information and communication technologies can engage students, enhance achievement, create new learning possibilities and extend interaction with local and global communities. Consequently, these allow students to demonstrate high order of thinking.

However, while the preceding discussions suggest rich tasks as activity in learning mathematics with technology, constructivist leaning theory as the approaches or productive pedagogies as framework of teaching, it is also realized that many problems and difficulties associated with the issues will be emerged. This includes sustained implementation of rich task and productive pedagogy is neither a simple task for teachers nor students (Moeld,
2000). This is especially required deep commitment of mathematics teachers in applying those activities. Additionally, the implementation of these approaches will be problematic if the current curriculum emphasizes breadth of content over depth. It is believed that continuous professional development with focus on Technology, Pedagogy and Content Knowledge (TPACK) (Mishra \& Koehler, 2008) can minimize these problems.

\section{CONCLUSION}

Using technology to improve mathematics education is not a simpler way. There are many things that need to be considered. This is especially to ensure technology is used effectively to enhance students' learning and teachers' practice of mathematics. It is found that the place for technology is clearly mandated in current Australian mathematics curriculum to support students learning of mathematics, but there is no specific direction of how it might be implemented in the classroom. This is indication that availability of technological resources and policy merely does not guarantee the enhancement of leaning and teaching mathematics. This means that the proposed curriculum (ACARA) is still challenged since it focuses on content based learning and not given any indication of the pedagogy to be used to deliver curriculum. More focus on rich mathematical tasks and productive pedagogies as proposed by many educational researchers are suggested. It is also emphasized that the importance of professional development that foster both technological competence and pedagogy flexibility is needed.

\section{FUTURE DIRECTION}

To maximize the effectiveness of technology as a tool to enhance mathematics learning in the classroom, this paper suggests some probable solutions. This includes having a shared vision among educational stakeholders. In doing so, it is hoped that no remain gap between policy and reality as well as successful implementation of technology in teaching and learning mathematics will be achieved. Second, mathematics teachers need to be equipped with knowledge of mathematics, general pedagogical knowledge, technical knowledge and classroom management to be able to teach mathematics with technology effectively. Third, education policy makers must incorporate technology selectively into educational reform for improvement and continue to study its progress over time. This effort then can be facilitated through intensive process of research and discussion. These efforts then can help target initial applications of technology that are most likely to improve learning within overall programs of experimental reform. Fourth, it is essential when contemplating any curriculum change to have clear goals about what might be achieved. The field needs to understand the kinds of learning outcomes that technology can enhance and the circumstances under which that enhancement will be realized in practice (Means, 2010). Fifth, it is necessary to extend curriculum scripts to provide for proactive structuring and responsive shaping of activity 
and reworking lesson agenda such as time allocation for mathematics learning (Ruthven et al., 2009). Regarding these recommendation, this paper recognizes that the recommendations are relevant with many suggestions that can be found in many literatures (Assude et al., 2009; Chinnapan, 2006; Hew \& Brush, 2006; Roschelle et al., 2000; Ruthven et al., 2009).

It is argued that all of these can facilitated by continues professional development (PD). It is believed that PD not only facilitates all above recommendations into real action but also solves other problems that occur due to technology integration both in applying rich tasks and productive pedagogy. Additionally, as it is known that mathematics learning and teaching with digital technology is still young, direct changes is difficult to achieve. However, by conducting this continuous professional development perhaps in the next 20 years we will see some more substantial changes in the nature of mathematics and mathematics learning in digital technology learning environment.

\section{REFERENCES}

ACARA, (2010). Mathematics Curriculum: Draft Consultation version 1.1.0, Australian Curriculum Assessment and Reporting Authority, Viewed on 15 September 2010. <http://www.acara.edu.au/curriculum.html>

Assude, T. (2005). Time management in the work economy of a class. A case study: integration of cabri in primary school mathematics teaching. Educational Studies in Mathematics, 59(1), 183-203.

Assude, T., Buteaw, C., \& Forgasz, H. (2010) Factors influencing implementation of technology-rich mathematics curriculum and practices, In C. Hoyles and J. B. Lagrange (eds.), Mathematics Education and Technology-Rethinking the Terrain. (pp. 405-419). LLC, Springer Science + Business Media.

Ben-El-Mechaiekh, H., Buteau, C., \& Ralph, W. (2007). MICA: a novel direction in undergraduate mathematics teaching. Canadian Mathematics Society Notes, 39(6), 9-11.

Borko, H., Whitcomb, J., \& Liston (2009). Wicked problems and other thoughts on issues of technology and teacher learning. Journal of Teacher Education, 60 (1), 3-7.

Brandy, L., \& Kennedy K. (2007) Curriculum Construction 3th Edition. Pearson Education Australia.

Chinnapan, M. (2006). Using the productive pedagogies framework to build a community of learners online in mathematics education. Distance Education, 27(3), 355-366.

Commonwealth of Australian (2003). Australia's teachers: Australia's future. Advancing innovation, science, technology and mathematics. Agenda for action. Viewed on 26 November $2004<$ www.dest.gov.au/schools/teachingreview>

Ertmer, P. A. (2005). Teacher pedagogical beliefs: The final frontier in our quest for technology integration? Educational Technology Research and Development, 53(4), 25-39.

Fergusson, S (2009). Same tasks, different paths: catering for students' diversity in mathematics classroom. APMC, 14 (2), 32-36.

Fitriati, F and Novita, R (2018). Designing student worksheet for rich mathematical tasks. Journal of Physics: Conference Series 0188 012029.

Forgasz, H.J., Griffith, S., \& Tan, H. (2006). Gender, equity, teachers, students, and technology use in secondary mathematics classrooms. In C. Hoyles, J. Lagrange, L. H. Son \& N. Sinclair (Eds.), Proceedings for the Seventeenth ICMI Study Conference: Technology Revisited, Hanoi University of Technology, 3rd-8th December, 2006 (c82).

Goos, M., \& Bennison, A. (2006) Technology in secondary mathematics classrooms: A survey of Queensland teachers. Paper presented at the annual conference of Australian Association for Research in Education, Adelaide 27-30 November.

Goos, M., Soury-Lavergne, S., Assude, T., Brown, J., Kong, C., et al (2010) Teacher and Teaching: Theoritical Perpective and Issues Concerning Classroom Implementation. In C. Hoyles and J. B. Lagrange (eds.), Mathematics Education and Technology-Rethinking the Terrain. (pp. 311-328). LLC, Springer Science + Business Media.

Goos, M. (2010). A sociocultural framework for understanding technology integration in secondary school mathematics. PNA, 5(1), 1-10.

Hew, K. F., \& Brush, T. (2007). Integrating technology into K-12 teaching and learning: current knowledge gaps and recommendation for future research. Education Tech Research Dev,55, 223-235.

Julie, C., Leung, A., Chi Thanh, N., Posadas, L. S., Sacritan, A.I., Sumenow, A. (2010). Some regional development in access and implementation of digital technologies and ICT. In C. Hoyles and J. B. Lagrange (eds.), Mathematics Education and Technology-Rethinking the Terrain. (pp. 311-328). LLC, Springer Science + Business Media.

Kaput, J. (2007). Technology is becoming infrastructure in mathematics education. Viewed on 20 October 2010.http://www.icme-organisers.dk/tsg15/ICME_Plenary_Kaput.pdf

Kendal, M., \& Stacey, K. (2002) Teachers in transition: Moving towards CAS-supported classrooms. ZDM, 34 (5), 196-203.

Laborde, C., \& StraBer, R. (2010) Place and use of new technology in teaching of mathematics: ICMI activities in the past 25 years. ZDM Mathematics Education, 42, 121-133.

Leedy, P. D., \& Ormrod, J. E. (2010) Practical Research: Planning and Design, Pearson Education, Upper Saddle River, New Jersey.

Lim, J. P (2007), Effective integration of ICT in Singapore schools: Pedagogy and policy implication. Education Technology Research Dev, $55,83-116$.

Lynch, J. (2006) Assessing effects of technology usage on mathematics learning. Mathematics Education Research Journal, 18 (23), 29-43.

Matzen, N.J., \& Edmunds, J. A (20000. Technology as catalyst for change: The role of professional development. Journal of Research on Technology Education, 39(4), 417-430.

Mishra, P. \& Koehler, M.J. (2006) Technological pedagogical content knowledge: A framework for teacher knowledge. Teacher College Record, 108 (6), 1017-1054.

Moulds, P. (2004). Rich Tasks. Educational Leaderships, 51 (4), 75-78.

Naeve, A., \& Nilson, M. (2004). ICT enhanced mathematics education: In the framework of a knowledge manifold. Viewed on 20 October 2010.http://citeseerx.ist.psu.edu/viewdoc/download?.doi=10.1.1.63.806 7\&rep\&rep1\&type=pdf

NRICH Specialist in Mathematics. (2010). University of Cambridge. Viewed on 15 October 2010. < http://nrich.maths.org/public/index.php> 
Newhouse, C. P. (2001). A follow-up study of students using portable computers at a secondary school. British Journal of Educational Technology, 32(2), 209-219.

Oates, G. (2009). Integrated technology in the undergraduate curriculum: a case study of computer algebra system. Unpublished Dissertation of Doctor of Philosophy in Mathematics Education, The University of Auckland.

Olson, J. \& Barrett, J. (2004). Coaching teachers to implement mathematics reform recommendations. Mathematics Teacher Education and Development, 6, 63-78.

Peirce, R., \& Ball, L. (2009). Perception that may affect teachers' intention to use technology in secondary mathematics classes. Educ Stud Math, 71, 299-317.

Queensland Educational Department (2002), Education Queensland Department's New Basics project: Productive pedagogies. Viewed on 15 October 2010. http://education.qld.gov.au

Roschelle, J. M., Pea, R.D., Hoadley, C.M., Gordin, D.N., \& Means, B.M. (2000). Changing how and what children learn in school with computer-based technology. Children and Computer Technology, 76-101.

Roschelle, J., Schechman, N., Tatar, D., Hedegus, S., Hopkins, B., Empson, S., Knudsen, J., Gallgher, L. P. (2010). Integration of Technology, Curriculum and Professional Development for Advancing Middle School Mathematics: Three Large-Scale Studies. American Educational Research Journal, 20(10), 1-46.

Schoenfeld, A. H. (1992). Learning to think mathematically: Problem solving, metacognition, and sense-making in mathematics. In D. Grouws (Ed.), Handbook for Research on Mathematics Teaching and Learning (pp. 334-370). New York: MacMillan.

Snoeyink, R., \& Ertmer, P. A. (2001-02). Thrust into technology: How veteran teachers respond. Journal of Educational Technology Systems, 30(1), 85-111.

Stacey, K. (2005). Accessing Results from Research on Technology in Mathematics Education. Australian Senior Mathematics Journal. 19 (1), 8-15.

Stein, M. K., Grover, B. W. \& Henningsen, M. (1996). Building student capacity for mathematical thinking and reasoning: An analysis of mathematical tasks used in reform classrooms. American Educational Research Journal, 33(2), 455-488.

Thomas, M., Tyrrell, J., \& Bullock, J (1996). Using computer in mathematics classroom: The roles of teacher. Mathematics Education Research Journal, 8 (1), 38-57.

Victorian Curriculum \& Assessment Authority. (2002). Sample units: Information and communication technology-Mathematics. Viewed on October 13, 2010, http://www.vcaa.vic.edu.au/preplO/csf/support/icts/ictspd.htmlttmaths

Victorian Curriculum \& Assessment Authority. (2005). Information and communication technology in discipline-based learning-Mathematics, Viewed on October 13, 2010,<http://vels.vcaa.vic.edu.au/essential/discipline/mathematics /index.html> 